DOI: $10.17805 / z p u .2018 .1 .14$

\title{
Источниковедческие умения аспирантов в аспекте текстовой компетентности
}

\author{
О. А. КОСИНОВА \\ МОСКОВСКИЙ ГУМАНИТАРНЫЙ УНИВЕРСИТЕТ
}

Реформа аспирантуры в российской системе образования подразумевает совершенствование содержания образования и способов преподавания на основе компетентностного подхода. Способность аспирантов самостоятельно осуществлять научно-исследовательскую деятельность рассмотрена как ключевое умение, сообразное цели подготовки кадров высшей квалификации. Способности к критическому анализу и оценке современных научных достижений, генерированию новых идей, проектированию и осуществлению научных исследований, в том числе междисциплинарных, владение методологией и методами исследования и другие компетенции рассмотрены как компоненты, представляющие собой различные стороны культуры научного исследования.

Текст научной работы выступает и как объект, и как результат познавательной деятельности аспирантов. Авторство в тексте рассматривается в качестве критерия познавательной самостоятельности обучаемых. Языковая компетентность и ее составляющая - текстовая компетентность представляют собой результаты формируемых умений, показатель личностной вовлеченности в научно-исследовательскую работу. Источниковедческие умения рассмотрены на материале дисциплины «Современные информационные и библиотечные ресурсы» как компонент текстовой компетентности обучающихся аспирантуры в единстве: текстовоспринимающей, интерпретационной, текстообразующей.

Раскрытию субъектности аспирантов в учебном взаимодействии способствует система учебных заданий, охватывающая все стороны проявления их индивидуальности. Гносеологический потенциал привлекаемых аспирантами документов раскрывается благодаря формируемым учебным действиям, базирующимся на структуре источниковедческого знания, с одной стороны, и содержательному наполнению самостоятельно выполняемых заданий - с другой. Системность заданий формируется с учетом структуры учебной деятельности, этапности в переходе от воспроизводящей к творческой деятельности, видов текстовой деятельности, структуры источниковедческого знания. Систему умений и навыков в самом общем плане определяют виды учебной деятельности, объект учебной деятельности, совокупность компетенций.

Ключевые слова: кадры высшей квалификации; федеральный государственный образовательный стандарт; научное исследование; текстовая компетентность; источниковедческое умение; аспирантура

\section{BВEАЕНИЕ}

\begin{abstract}
огласно действующим стандартам в российском образовании обучающиеся по образовательным программам аспирантуры должны овладеть универсальными и общепрофессиональными компетенциями. Признавая за аспирантами наивысший Аля вузовского образования уровень учебной деятельности, отметим, что в таком случае их учебные действия должны характеризоваться направленностью на анализ и управление своей познавательной деятельностью, способностью к самостоятельной исследовательской работе. Представляется возможным рассмотреть логику выявления совокупности умений и (или) навыков на примере дисциплины «Современные информационные и библиотечные ресурсы», которую изучают аспиранты второго курса.
\end{abstract}

\section{НОРМАТИВНАЯ ХАРАКТЕРИСТИКА ИССАЕАОВАТЕАЬСКИХ КОМПЕТЕНЦИЙ}

Компетенция является комплексным понятием, включающим в себя знания, умения и навыки. Как ключевое понятие стандартов, оно представлено в документах 
в связи с понятием видов профессиональной деятельности, к которым готовятся выпускники определенной образовательной программы. Сравнительный анализ федеральных государственных образовательных стандартов высшего образования (ФГОС ВО) по направлениям, реализуемым в Московском гуманитарном университете (МосГУ), показал единство моделей подготовки аспирантов. Способность к научно-исследовательской деятельности - наиболее близкому виду профессиональной деятельности с точки зрения цели и задач названной дисциплины (Косинова, 2015) - содержательно представлена универсальными и общепрофессиональными компетенциями.

Среди универсальных компетенций следует отметить:

- способность к критическому анализу и оценке современных научных достижений, генерированию новых идей при решении исследовательских и практических задач, в том числе в междисциплинарных областях;

- способность проектировать и осуществлять комплексные исследования, в том числе междисциплинарные, на основе целостного системного научного мировоззрения с использованием знаний в области истории и философии науки.

Среди общепрофессиональных необходимо отметить общие для всех направлений краткие формулировки следующих компетенций:

- владение методологией и методами исследования;

- владение культурой научного исследования, в том числе с использованием новейших информационно-коммуникационных технологий (Приказ ..., 2014adgh: Электронный ресурс);

- способность самостоятельно осуществлять научно-исследовательскую деятельность в соответствующей профессиональной области с использованием современных методов исследования и информационно-коммуникационных технологий;

- способность к разработке новых методов исследования и их применению в самостоятельной научно-исследовательской деятельности (Приказ ..., 2014abcefgh: Электронный ресурс).

Названная дисциплина предполагает развитие у аспирантов способности целенаправленно и результативно работать с большим количеством информации различного происхождения, содержания, стилей. Ее общим свойством является по меньшей мере одно - все это тексты.

ТЕКСТ КАК ФОРМА СТРУКТУРИРОВАНИЯ СУБЪЕКТИВНО ЗНАЧИМОЙ ИНФОРМАЦИИ И ВЫРАЖЕНИЯ ИССАЕАОВАТЕАЬСКОЙ ПОЗИЦИИ ОБУЧАЕМЫХ

Современные гуманитарии едины в выводе о том, что язык - средство конструирования мира. Убеждения в том, что язык формирует мысль и природа языка общественная (Потебня, 1989: 5), закрепились в качестве выводов в современной отечественной педагогике, применяющей когнитивный подход для реконструкции соответствующих структур участников коммуникаций по данным внешней языковой формы (Аукацкий, 2017: 24). Языковая компетентность и ее составляющая - текстовая компетентность как результаты познавательной деятельности проявляют себя в устной и письменной речевой активности обучающихся. Языковая картина мира личности представляет собой версию социальной реальности, специфическую ввиду ее рефлексивной природы, множественных интерпретаций окружающей действительности, значимости индивидуальных смыслов. Текст принципиально отли- 
чен от события, исторического факта: он всегда кем-то и с какой-то целью создан и тесно связан с внетекстовой реальностью (Иотман, 2001: 336). Поскольку текст неотделим от субъекта как его носителя, постольку языковая картина мира каждой личности индивидуальна.

Вал. А. Ауков и Вл. А. Ауков обратили внимание на «субъективизацию современной науки» как естественное следствие развития современной культуры, обусловленное индивидуальными способами восприятия и обработки огромных массивов информации (Ауков Вал., Ауков В., 2013: 3). Анализ дидактического назначения знакомства аспирантов с информационными и библиотечными ресурсами в ракурсе способности выразить себя в тексте дает возможность подойти дифференцированно к таким явлениям, как логика текста; отношение к информации, заключенной в текстах, в том числе, разделить замысел и исполнение; перейти от знания (информационного потенциала источника) к пониманию авторской позиции. Аидактически языковая картина мира обучающихся, воплощенная в созданные ими тексты, является объектом учебного взаимодействия преподавателя и аспирантов. Текст выступает и как объект, и как результат исследовательской работы обучающихся.

\section{СИСТЕМА ИСТОЧНИКОВЕАЧЕСКИХ УМЕНИЙ АСПИРАНТОВ}

Формирование способности к созданию текста является вопросом обучающей технологии. Умение создать текст (способность к текстопорождению) рассматривается специалистами в единстве трех видов текстовой деятельности: текстовоспринимающей, интерпретационной, текстообразующей (Богданова (Симакова), 2017: 106).

Перед современным источниковедением стоят две основные задачи - эвристическая и аналитическая. Эвристическая задача - это ориентирование в многообразии исторических источников, их классификация, изучение совокупности источников, отложившихся в ходе исторического процесса, как в целом, так и в частности для отдельных исторических эпох конкретных стран или регионов. Аналитическая задача - это разработка методов анализа исторических источников, получения из них достоверной и возможно более полной информации, а также методов оценки источников с данной точки зрения (Источниковедение ..., 1998: 64). При этом документы, как носители социально значимой информации и артефакты, выполняют в исследовании несколько функций: ориентировочную, аналитическую, структурирующую и классифицирующую (Ааппо-Аанилевский, 1920; Источниковедение ... , 1998). Аля того чтобы документ выполнил свое предназначение в исследовании, его функционал должен быть освоен обучающимися в качестве ориентировочной основы действий. Таким образом, функции документов как исторических источников определяют направленность и виды работ будущих исследователей.

Опора на структуру учебной деятельности (Эльконин, 1989: 212-219) обучаемых позволяет подойти к вопросу формирования названных выше компетенций поэтапно: от осознания учебной задачи (исследовательской проблемы) и способов ее разрешения до действия самооценки, включая мотивы обращения к информационному ресурсу. Если задание подразумевает полную структуру учебной деятельности, то обращение к конкретной функции документа определяет содержание познавательной деятельности аспирантов постольку, поскольку в заданиях представлены осмысленный и субъективно значимый понятийный аппарат исследования, языковая картина будущей научной работы. 
В самом широком плане учение предполагает наличие у субъектов способности к саморазвитию и самосовершенствованию путем сознательного и активного присвоения нового социального опыта. С точки зрения компетентностного подхода в профессиональной области наиболее ценной является способность субъекта самостоятельно устанавливать связи между своими знаниями, умениями, навыками и реальной профессиональной ситуацией. Именно на данном умении базируется современное представление об успешных действиях субъекта в процессе профессиональной самореализации. Авторство в тексте дидактически может рассматриваться в качестве критерия познавательной самостоятельности обучаемых: чем более авторским является текст, тем более аспирант независим как исследователь. При этом понятие о тексте - самое широкое: от поисковых запросов обучаемых до более сложных форм, появляющихся в результате аннотирования, описания, реферирования, библиографического анализа и других видов работы с первоисточниками.

Наибольший объем работы при освоении информационных ресурсов различных типов и видов связан с интерпретацией содержания источников. И. Я. Аернер, историк-медиевист, автор одной из концепций проблемного обучения, соотносил владение умением интерпретировать тексты с уровнями, характеризующими самостоятельность мышления. Они соответствуют видам деятельности по опознанию и выявлению связей внутри текстов. Углубление в текст сопряжено с выявлением сначала поверхностных, а затем скрытых смысловых связей. Обнаружение последних требует творческого подхода (Прогностическая концепция ..., 1994).

В отечественной дидактике обоснованы результаты учебной деятельности. К ним относятся четыре уровня опыта: опыт познавательной деятельности, фиксируемый в форме ее результатов - знаний; опыт репродуктивной деятельности, фиксируемый в форме способов ее осуществления - умений и навыков; опыт творческой деятельности - в форме умений принимать нестандартные решения в проблемных ситуациях; опыт осуществления эмоционально-ценностных отношений - в форме личностных ориентаций (Иернер, 1981). Наличие данного опыта в познавательном багаже обучающихся означает полноту их исследовательского потенциала.

На занятиях по дисциплине документы рассматриваются прежде всего как источники информации. Однако тексты - явления глубоко личностные. Включение в систему заданий учебных задач на выработку у аспирантов своего отношения к источникам, нацеленных на рефлексию учебного материала, имеет целью выявление личностной позиции обучающихся и позволяет проверить не только логическое осмысление материала, но и включение его в ценностную систему будущих исследователей.

Кроме того, довольно часто при определении гносеологического значения того или иного документа аспиранты опираются не на первоисточник, а на «источник об источнике», проще говоря, на учебники, где уже изложен анализ и дана оценка тому или иному тексту. Включение заданий на выявление личностной позиции обучаемых позволяет рассмотреть документ, так сказать, на индивидуальном уровне и тем самым определить его эвристический потенциал.

Извлечение смысла из текстов создает необходимую познавательную основу для навыков систематизации источников: ранжирования и классификации. Обе способности относятся к аналитической части источниковедческой работы, поскольку, во-первых, связаны с их содержанием (в особенности классификация). Во-вторых, 
обеспечивают структурирование источниковой базы научного исследования, благодаря чему позволяют обучающимся перейти от репрезентативной выборки информационных и библиографических ресурсов к их осознанному предметно-тематическому отбору. Овладение данным навыком формирует качество избирательности исследователя, связанное с пониманием темы и содержания научной работы. Формирующееся эмоционально-ценностное отношение к своей работе, обеспечивающее единство и системность структуры учебной деятельности аспирантов, может быть проверено заданиями на понимание значимости своего исследования.

Изучение разнородных по характеру текстов, а также установление взаимосвязей между различными видами информации приводит к формированию разных показателей качества знаний (глубины, гибкости, системности и др.), соотносимых с требуемыми компетенциями и проверяемых соответствующими умениями. Поскольку каждое качество проявляет разные свойства мышления, постольку это позволяет конструировать задания на формирование и диагностику каждого отдельного качества и тем самым развивать мышление, проявляющееся при выполнении каждого задания, системы заданий. Совокупность показателей качеств знаний создает необходимую познавательную основу для проявления творческого подхода, т. е. для создания собственного текста. Творческий уровень мышления характеризуется самостоятельным переносом ранее усвоенных знаний и умений в новую ситуацию; видением новой проблемы в знакомой ситуации; осознанием структуры объекта; поиском альтернативы решения или способа решения; комбинированием ранее известных способов решения проблемных задач, появлением преобразующих учебных действий. Соотнесение компетенций с учебными действиями (умениями и навыками) обучающихся, их представленность в содержании обучения по дисциплине в форме системы заданий, структурированной по видам деятельности, позволяет решать главную задачу преподавателя - управление мыслительной активностью аспирантов.

\section{ЗАКАЮЧЕНИЕ}

Источниковедческие умения и навыки рассматриваются как часть более общей способности - текстовой культуры дичности. Систему умений и навыков в самом общем плане определяют объект учебной деятельности, виды учебной деятельности, совокупность компетенций.

Текстовая компетентность проявляет себя как личностное качество. Раскрытию субъектности аспирантов в учебном взаимодействии способствует система учебных заданий, охватывающая все стороны проявления их индивидуальности. Гносеологический потенциал привлекаемых аспирантами документов раскрывается на занятиях благодаря формируемым учебным действиям, базирующимся на структуре источниковедческого знания, с одной стороны, и содержательному наполнению самостоятельно выполняемых заданий - с другой.

\section{СПИСОК АИТЕРАТУРЫ}

Богданова (Симакова), Е. С. (2017) Работа над историзмами в ходе формирования умений текстовой деятельности старших школьников // Психолого-педагогический поиск. № 1 (41). C. $105-113$.

Источниковедение: Теория. История. Метод. Источники российской истории : учеб. пособие для гуманит. спец. (1998) / И. Н. Аанилевский, В. В. Кабанов, О. М. Медушевская, М. Ф. Румянцева ; Рос. гос. гуманит. ун-т; Ин-т «Открытое общество». М. : РГГУ. 701 с. 
Косинова, О. А. (2015) Современные информационные и библиографические ресурсы : Раб. программа дисциплины. Б1.В.АВ.1(1). Направление подготовки. 44.06.01 «Образование и пед. Науки». Направ. (профиль) подготовки - «Общая педагогика, история педагогики и образования». Квалификация. Исследователь. Преподаватель-исследователь. Форма обучения - очная, заочная. М. : Изд-во Моск. гуманит. ун-та. 26 с.

Ааппо-Аанилевский, А. С. (1920) Очеркъ русской дипломатики частныхъ актовъ. Аекции, чит. слушателям «Архивных курсов» при Петрогр. археол. ин-те в 1918 г. Петроград : Б. и., 2-я Гос. тип. [2], 188, [1] с.

Иернер, И. Я. (1981) Аидактические основы методов обучения. М. : Педагогика. 186 с.

Иотман, Ю. М. (2001) Семиосфера. Культура и взрыв. Внутри мыслящих миров. Статьи. Исследования. Заметки. СПб. : Искусство-СПБ. 703 с.

Аукацкий, М. А. (2017) Образовательный дискурс: от иллюзорного понимания к реальному постижению // Психолого-педагогический поиск. № 1 (41). С. 15-28.

Ауков, Вал. А., Ауков, Вл. А. (2013) Тезаурусный подход в гуманитарном знании // Тезаурусный анализ мировой культуры : сб. науч. трудов. Вып. 25 / под общ. ред. Вл. А. Аукова. М. : ИзА-во Моск. гуманит. ун-та. 160 с. С. 3-13.

Потебня, А. А. (1989) Слово и миф. М. : Правда. 622, [1] с.

Приказ Министерства образования и науки РФ от 30 июля 2014 г. № 897 «Об утверждении федерального государственного образовательного стандарта высшего образования по направлению подготовки 37.06.01 Психологические науки (уровень подготовки кадров высшей квалификации)». С изм. и доп. от 30 апреля 2015 г. (2014а) [Электронный ресурс]// Координационный совет учебно-методических объединений и научно-методических советов высшей школы // Портал Федеральных государственных образовательных стандартов высшего образования. URL: http://fgosvo.ru/fgosvo/92/91/4 (дата обращения: 10.07.2017).

Приказ Министерства образования и науки РФ от 30 июля 2014 г. № 898 «Об утверждении федерального государственного образовательного стандарта высшего образования по направлению подготовки 38.06.01 Экономика (уровень подготовки кадров высшей квалификации)». С изм. и доп. от 30 апреля 2015 г. (2014b) [Электронный ресурс]/ Координационный совет учебно-методических объединений и научно-методических советов высшей школы // Портал Федеральных государственных образовательных стандартов высшего образования. URL: http:// fgosvo.ru/fgosvo/92/91/4 (дата обращения: 10.07.2017).

Приказ Министерства образования и науки РФ от 30 июля 2014 г. № 899 «Об утверждении федерального государственного образовательного стандарта высшего образования по направлению подготовки 39.06.01 Социологические науки (уровень подготовки кадров высшей квалификации)». С изм. и доп. от 30 апреля 2015 г. (2014c) [Электронный ресурс] / Координационный совет учебно-методических объединений и научно-методических советов высшей школы // Портал Федеральных государственных образовательных стандартов высшего образования. URL: http://fgosvo.ru/fgosvo/92/91/4 (дата обращения: 10.07.2017).

Приказ Министерства образования и науки РФ от 30 июля 2014 г. № 902 «Об утверждении федерального государственного образовательного стандарта высшего образования по направлению подготовки 44.06.01 Образование и педагогические науки (уровень подготовки кадров высшей квалификации)». С изм. и доп. от 30 апреля 2015 г. (2014d) [Электронный ресурс]/ Координационный совет учебно-методических объединений и научно-методических советов высшей школы // Портал Федеральных государственных образовательных стандартов высшего образования. URL: http://fgosvo.ru/fgosvo/92/91/4 (дата обращения: 10.07.2017).

Приказ Министерства образования и науки РФ от 30 июля 2014 г. № 904 «Об утверждении федерального государственного образовательного стандарта высшего образования по направлению подготовки 46.06.01 Исторические науки и археология (уровень подготовки кадров высшей квалификации)». С изм. и доп. от 30 апреля 2015 г. (2014е) [Электронный ресурс]/ Координационный совет учебно-методических объединений и научно-методических советов высшей школы // Портал Федеральных государственных образовательных стандартов высшего образования. URL: http://fgosvo.ru/fgosvo/92/91/4 (дата обращения: 10.07.2017). 
Приказ Министерства образования и науки РФ от 30 июля 2014 г. № 905 «Об утверждении федерального государственного образовательного стандарта высшего образования по направлению подготовки 47.06.01 Философия, этика и религиоведение (уровень подготовки кадров высшей квалификации)». С изм. и доп. от 30 апреля 2015 г. (2014f) [Электронный ресурс]/ Координационный совет учебно-методических объединений и научно-методических советов высшей школы // Портал Федеральных государственных образовательных стандартов высшего образования. URL: http://fgosvo.ru/fgosvo/92/91/4 (дата обращения: 10.07.2017).

Приказ Министерства образования и науки РФ от 22 августа 2014 г. № 1038 «Об утверждении федерального государственного образовательного стандарта высшего образования по направлению подготовки 51.06.01 Культурология (уровень подготовки кадров высшей квалификации)». С изм. и доп. от 30 апреля 2015 г. (2014g) [Электронный ресурс] / Координационный совет учебно-методических объединений и научно-методических советов высшей школы // Портал Федеральных государственных образовательных стандартов высшего образования. URL: http://fgosvo.ru/fgosvo/92/91/4 (дата обращения: 10.07.2017).

Приказ Министерства образования и науки РФ от 5 декабря 2014 г. № 1538 «Об утверждении федерального государственного образовательного стандарта высшего образования по направлению подготовки 40.06.01 Юриспруденция (уровень подготовки кадров высшей квалификации)». С изм. и доп. от 30 апреля 2015 г. (2014h) [Электронный ресурс] / Координационный совет учебно-методических объединений и научно-методических советов высшей школы // Портал Федеральных государственных образовательных стандартов высшего образования. URL: http://fgosvo.ru/fgosvo/92/91/4 (дата обращения: 10.07.2017).

Прогностическая концепция целей и содержания образования (1994) / [Ю. Б. Алиев, В. Г. Богин, И. К. Журавлев и др.] ; под науч. ред. И. Я. Аернера, И. К. Журавлева. М. : ИТПИМИО. 131 с.

Эльконин, А. Б. (1989) Избранные психологические труды. М. : Педагогика. 560 с.

Аата поступления: 25.10.2017 2.

POSTGRADUATE STUDENTS' SOURCE-STUDY SKILLS

IN THE ASPECT OF TEXTUAL COMPETENCE

O. A. KOSINOVA

MOSCOW UNIVERSITY FOR THE HUMANITIES

A reform of postgraduate school within the Russian education system implies improving the content of education and methods of teaching on the basis of the competence approach. Postgraduate students' ability to independently carry out research activity is considered to be a key skill that is suited to the purpose of training highly-qualified personnel. The ability to critically analyse and evaluate modern scientific achievements, generate new ideas, design and implement scientific research, including interdisciplinary, master methodology and methods of research, and other competencies are considered to be components representing different sides of the culture of scientific research.

The text of a paper acts as both the object and the result of postgraduate students' cognitive activity. The authorship in the text is considered to be a criterion of students' cognitive independence. Linguistic competence and its component - textual competence - are results of the skills that are being formed, a measure of personal involvement in scientific research work. Source-study skills are considered on the material of the discipline "Modern Information and Library Resources" as a component of postgraduate students' textual competence in the unity: text-perceiving, interpretational, and text-producing.

The disclosure of postgraduate students' subjectivity in the teaching interaction is encouraged by the system of educational tasks, covering all aspects of manifestation of their personality. The epistemological potential of documents utilised by postgraduate students is revealed due to the developing educational actions that are based on the structure of the source-study knowledge on the one hand, and on the content of the independently fulfilled tasks on the other hand. The systematic nature of the tasks is formed considering the structure of educational activity, phasing in the transition from reproducing to creative activity, the types of textual activity, and the structure of source-study knowledge. 
A system of abilities and skills in the most general terms is defined by the types of educational activity, the object of educational activity, and the set of competencies.

Keywords: highly-qualified personnel; Federal State Educational Standard; scientific research; textual competence; source-study ability; postgraduate school

\section{REFERENCES}

Bogdanova (Simakova), E. S. (2017) Rabota nad istorizmami v khode formirovaniia umenii tekstovoi deiatel'nosti starshikh shkol'nikov. Psikbologo-pedagogicheskii poisk, no. 1 (41), pp. 105-113. (In Russ.).

Istochnikovedenie: Teoriia. Istoriia. Metod. Istocbniki ros. istorii : ucheb. posobie dlia gumanit. spets. (1998) / I. N. Danilevskii, V. V. Kabanov, O. M. Medushevskaia and M. F. Rumiantseva. Moscow, RGGU. 701 p. (In Russ.).

Kosinova, O. A. (2015) Sovremennye informatsionnye $i$ bibliograficheskie resursy : Rab. programma distsipliny. B1.V.DV.1(1). Napravlenie podgotovki. 44.06.01 «Obrazovanie i ped. Nauki». Naprav. (profil’) podgotovki - «Obshchaia pedagogika, istoriia pedagogiki i obrazovaniia». Kvalifikatsiia. Issledovatel'. Prepodavatel'-issledovatel'. Forma obucheniia-ochnaia, zaochnaia. Moscow, MosGU. 26 p. (In Russ.).

Lappo-Danilevskii, A. S. (1920) Ocherk «russkoi diplomatiki chastnykb» aktov». Lektsii, chit. slushateliam "Arkbivnykb kursov» pri Petrogr. arkbeol. in-te v 1918 g. Petrograd, B. i., 2-ia Gos. tip. [2], 188, [1] p. (In Russ.).

Lerner, I. Ia. (1981) Didakticheskie osnovy metodov obucheniia. Moscow, Pedagogika. 186 p. (In Russ.).

Lotman, Iu. M. (2001) Semiosfera. Kul'tura i vzryv. Vnutri mysliashchikb mirov. Stat'i. Issledovaniia. Zametki. St. Petersburg, Iskusstvo-SPB. 703 p. (In Russ.).

Lukatskii, M. A. (2017) Obrazovatel'nyi diskurs: ot illiuzornogo ponimaniia k real'nomu postizheniiu. Psikbologo-pedagogicheskii poisk, no. 1 (41), pp. 15-28. (In Russ.).

Lukov, Val. A., Lukov, Vl. A. (2013) Tezaurusnyi podkhod v gumanitarnom znanii. In: Tezaurusnyi analiz mirovoi kul'tury: sb. nauch. trudov. Vol. 25 / ed. by Vl. A. Lukov. Moscow, Izdvo Mosk. gumanit. un-ta. 160 p. Pp. 3-13. (In Russ.).

Potebnia, A. A. (1989) Slovo i mif. Moscow, Pravda. 622, [1] p. (In Russ.).

Prikaz Ministerstva obrazovaniia i nauki RF ot 30 iiulia 2014 g. № 897 «Ob utverzhdenii federal'nogo gosudarstvennogo obrazovatel'nogo standarta vysshego obrazovaniia po napravleniiu podgotovki 37.06.01 Psikhologicheskie nauki (uroven' podgotovki kadrov vysshei kvalifikatsii)». S izm. i dop. ot 30 aprelia 2015 g. (2014a). Koordinatsionnyi sovet uchebno-metodicheskikh ob»edinenii i nauchno-metodicheskikh sovetov vysshei shkoly. Portal Federal' nykb gosudarstvennykb obrazovatel'nykb standartov vysshego obrazovaniia [online] Available at: http://fgosvo.ru/fgosvo/92/91/4 (access date: 10.07.2017). (In Russ.).

Prikaz Ministerstva obrazovaniia i nauki RF ot 30 iiulia 2014 g. № 898 «Ob utverzhdenii federal'nogo gosudarstvennogo obrazovatel'nogo standarta vysshego obrazovaniia po napravleniiu podgotovki 38.06.01 Ekonomika (uroven' podgotovki kadrov vysshei kvalifikatsii)». S izm. i dop. ot 30 aprelia 2015 g. (2014b) / Koordinatsionnyi sovet uchebno-metodicheskikh ob»edinenii i nauchnometodicheskikh sovetov vysshei shkoly. Portal Federal'nykh gosudarstvennykh obrazovatel'nykb standartov vysshego obrazovaniia [online] Available at: http://fgosvo.ru/fgosvo/92/91/4 (access date: 10.07.2017). (In Russ.).

Prikaz Ministerstva obrazovaniia i nauki RF ot 30 iiulia 2014 g. № 899 «Ob utverzhdenii federal'nogo gosudarstvennogo obrazovatel'nogo standarta vysshego obrazovaniia po napravleniiu podgotovki 39.06.01 Sotsiologicheskie nauki (uroven' podgotovki kadrov vysshei kvalifikatsii)». S izm. i dop. ot 30 aprelia 2015 g. (2014c) / Koordinatsionnyi sovet uchebno-metodicheskikh ob»edinenii i nauchno-metodicheskikh sovetov vysshei shkoly. Portal Federal'nykb gosudarstvennykb obrazovatel'nykb standartov vysshego obrazovaniia [online] Available at: http://fgosvo.ru/fgosvo/92/91/4 (access date: 10.07.2017). (In Russ.). 
Prikaz Ministerstva obrazovaniia i nauki RF ot 30 iiulia 2014 g. № 902 «Ob utverzhdenii federal'nogo gosudarstvennogo obrazovatel'nogo standarta vysshego obrazovaniia po napravleniiu podgotovki 44.06.01 Obrazovanie i pedagogicheskie nauki (uroven' podgotovki kadrov vysshei kvalifikatsii)». S izm. i dop. ot 30 aprelia 2015 g. (2014d) / Koordinatsionnyi sovet uchebno-metodicheskikh ob»edinenii i nauchno-metodicheskikh sovetov vysshei shkoly. Portal Federal'nykh gosudarstvennykh obrazovatel'nykb standartov vysshego obrazovaniia [online] Available at:: http://fgosvo.ru/ fgosvo/92/91/4 (access date: 10.07.2017). (In Russ.).

Prikaz Ministerstva obrazovaniia i nauki RF ot 30 iiulia 2014 g. № 904 «Ob utverzhdenii federal'nogo gosudarstvennogo obrazovatel'nogo standarta vysshego obrazovaniia po napravleniiu podgotovki 46.06.01 Istoricheskie nauki i arkheologiia (uroven' podgotovki kadrov vysshei kvalifikatsii)». S izm. i dop. ot 30 aprelia 2015 g. (2014e) / Koordinatsionnyi sovet uchebno-metodicheskikh ob'edinenii i nauchno-metodicheskikh sovetov vysshei shkoly. Portal Federal'nykb gosudarstvennykb obrazovatel'nykb standartov vysshego obrazovaniia [online] Available at: http://fgosvo.ru/fgosvo/92/91/4 (access date: 10.07.2017). (In Russ.).

Prikaz Ministerstva obrazovaniia i nauki RF ot 30 iiulia 2014 g. № 905 «Ob utverzhdenii federal'nogo gosudarstvennogo obrazovatel'nogo standarta vysshego obrazovaniia po napravleniiu podgotovki 47.06.01 Filosofiia, etika i religiovedenie (uroven' podgotovki kadrov vysshei kvalifikatsii)». S izm. i dop. ot 30 aprelia 2015 g. (2014f) / Koordinatsionnyi sovet uchebno-metodicheskikh ob'edinenii i nauchno-metodicheskikh sovetov vysshei shkoly. Portal Federal' nykb gosudarstvennykb obrazovatel'nykb standartov vysshego obrazovaniia [online] Available at: http://fgosvo.ru/fgosvo/92/91/ 4 (access date: 10.07.2017). (In Russ.).

Prikaz Ministerstva obrazovaniia i nauki RF ot 22 avgusta 2014 g. № 1038 «Ob utverzhdenii federal'nogo gosudarstvennogo obrazovatel'nogo standarta vysshego obrazovaniia po napravleniiu podgotovki 51.06.01 Kul'turologiia (uroven' podgotovki kadrov vysshei kvalifikatsii)». S izm. i dop. ot 30 aprelia 2015 g. (2014g) / Koordinatsionnyi sovet uchebno-metodicheskikh ob'edinenii i nauchnometodicheskikh sovetov vysshei shkoly. Portal Federal'nykb gosudarstvennykb obrazovatel'nykb standartov vysshego obrazovaniia [online] Available at: http://fgosvo.ru/fgosvo/92/91/4 (access date: 10.07.2017). (In Russ.).

Prikaz Ministerstva obrazovaniia i nauki RF ot 5 dekabria 2014 g. № 1538 «Ob utverzhdenii federal'nogo gosudarstvennogo obrazovatel'nogo standarta vysshego obrazovaniia po napravleniiu podgotovki 40.06.01 Iurisprudentsiia (uroven' podgotovki kadrov vysshei kvalifikatsii)». S izm. i dop. ot 30 aprelia 2015 g. $(2014 \mathrm{~h})$ / Koordinatsionnyi sovet uchebno-metodicheskikh ob'edinenii i nauchno-metodicheskikh sovetov vysshei shkoly. Portal Federal' nykh gosudarstvennykb obrazovatel' nykh standartov vysshego obrazovaniia [online] Available at: http://fgosvo.ru/fgosvo/92/91/4 (access date: 10.07.2017). (In Russ.).

Prognosticheskaia kontseptsiia tselei i soderzhaniia obrazovaniia (1994) / [Iu. B. Aliev, V. G. Bogin, I. K. Zhuravlev i dr.] ; ed. by I. Ia. Lerner and I. K. Zhuravlev. Moscow, ITPIMIO. 131 p. (In Russ.).

El'konin, D. B. (1989) Izbrannye psikbologicheskie trudy. Moscow, Pedagogika. 560 p. (In Russ.).

Submission date: 25.10 .2017$.

Косинова Оксана Анатольевна - доктор педагогических наук, доцент, профессор кафедры педагогики и психологии высшей школы Московского гуманитарного университета. Адрес: 111395, Россия, г. Москва, ул. Юности, д. 5. Тел.: +7 (499) 374-78-82. Эл. aдpec: ido@mosgu.ru

Kosinova Oksana Anatolievna, Doctor of Pedagogy, Associate Professor, Professor, Department of Pedagogy and Psychology of Higher School, Moscow University for the Humanities. Postal address: 5, Yunosti St., Moscow, Russian Federation, 111395. Tel.: +7 (499) 374-78-82. E-mail: ido@mosgu.ru 